\title{
DiSTFAG method robust to gross errors in monitoring displacements and strains in unstable reference systems
}

\author{
Waldemar Kamiński \\ Institute of Geodesy, University of Warmia and Mazury in Olsztyn \\ 1 Oczapowskiego St., 10-957 Olsztyn, Poland \\ e-mail: waldemar.kaminski@uwm.edu.pl
}

Received: 21 October 2010/Accepted: 8 March 2011

\begin{abstract}
The DiSTFA method (Displacements and Strains using Transformation and Free Adjustment) was presented in Kamiński (2009). The method has been developed for the determination of displacements and strains of engineering objects in unstable reference systems, as well as for examining the stability of reference points. The DiSTFAG (Gross errors) method presented in the paper is the extension of the DiSTFA method making it robust to gross errors. Theoretical considerations have been supplemented with an example of a practical application on a simulated 3D surveying network.
\end{abstract}

Keywords: displacements, strains, unstable reference system, gross error, covariance matrices

\section{Introduction}

Measurements of displacements and strains of engineering objects and their environment as well as the interpretation of the results obtained are one of the most important challenges in contemporary engineering surveying. During the measurements of displacements and strains, it may happen that the observations will be performed in unstable reference systems. It can also be the case that due to the technological process of the engineering construction, measurements will be performed from temporary sites where one will not be able to set up again the instrument in future. On the other hand, observations obtained at those sites will be needed for making decisions related to the entire technological process.

Geodetic surveys carried out in the above specified conditions can be contaminated by gross errors due to the coincidence of unfavourable factors. Without the possibility of repeating the measurements and, consequently, proper interpretation of their results, the measurements could become therefore worthless.

Chen et al. (1990) proposed a certain method for solving this problem. Generally speaking, the algorithm of the solution proposed is carried out in three stages. In the first stage surveying observations performed in various epochs are adjusted. The second stage involves identification of unstable reference points, by minimizing 
the first norm of displacement vectors established at reference points $\Sigma\left|d_{i}\right|=\min$. The third stage includes the estimation and statistical testing of the displacements, taking into consideration unstable reference points and the points of the examined object. This method, as reported by the authors, is widely used in monitoring networks. The method proposed is also used in practical applications (e.g. Gökalp and Tasci, 2009). The issue of applying reliability theory resistant to gross errors in networks established for monitoring displacements and strains has also been presented (Vaniček et al., 2001).

The present paper proposes a new method for analysing observations performed in unstable reference systems when observations are suspected of being contaminated by gross errors. This method has been conventionally named as DiSTFAG. The DiSTFAG method is the expansion of the DiSTFA method (Kamiński, 2008a, 2008b, 2009) which in turn is a 3D generalization of a certain concept of monitoring vertical displacements presented in Wiśniewski (1989).

Currently, the GPS satellite positioning is the most often applied measurement technology in surveying. When processing GPS positioning data vector components are adjusted with a quasi-diagonal $\mathbf{P}$ weight matrix. As a consequence, correlated obser- vations are subject to adjustment. Therefore, the elimination of observations suspected of gross errors should involve robust methods used for dependent observations. The issue of dependent observations resistant to gross errors has been presented (e.g. Xu, 1989; Yang, 1994; Yang et al., 2002).

The present study introduces a proposal of making the DiSTFA method robust to gross errors. However, the effectiveness, or the most favourable choice of equivalent weights applied in correlated observations is not analysed here. This issue will be a subject of further research by the author.

A theoretical discussion has been supplemented with an example of practical application on GPS simulated measurement results. The results of estimation obtained are the starting point for further, more detail theoretical and empirical analyses.

\section{The DiSTFA method}

The theoretical foundations of the DiSTFA method have been presented in (Kamiński, 2008a) and its characteristics was widely discussed (Kamiński, 2008b, 2009). The present study introduces theoretical considerations concerning the foundations of the DiSTFA method only in the scope necessary for proper understanding of the subject matter discussed here.

In the DiSTFA method, the estimated parameters (Kamiński, 2008a) are vectors: $\hat{\mathbf{s}}=\left[\hat{s}_{X_{i}}, \hat{s}_{Y_{i}}, \hat{s}_{Z_{i}}\right]^{\mathrm{T}},(i=1,2, \ldots, m)$ where $m$ is the number of points at which GPS observations were performed, and $\hat{\boldsymbol{\varepsilon}}=\left[\hat{\varepsilon}_{X}, \hat{\varepsilon}_{Y}, \hat{\varepsilon}_{Z}\right]^{\mathrm{T}}$. The vector $\hat{\mathbf{s}}$ corresponds to the distance between the random surface and an optimal plane while the vector $\hat{\boldsymbol{\varepsilon}}$ consists of rotation angles about the axes of the coordinate system. 
Assuming that vector components $\Delta X_{i, k}^{o b s}, \Delta Y_{i, k}^{o b s}, \Delta Z_{i, k}^{o b s},(i, k=1,2, \ldots, m)$ were observed using GPS technology, their adjusted values will be as follows

$$
\begin{aligned}
& \left(\Delta \hat{X}_{i, k}\right)^{j}=\left(\Delta X_{i, k}^{o b s}\right)^{j}+v_{\Delta X}^{j} \\
& \left(\Delta \hat{Y}_{i, k}\right)^{j}=\left(\Delta Y_{i, k}^{o b s}\right)^{j}+v_{\Delta Y}^{j} \\
& \left(\Delta \hat{Z}_{i, k}\right)^{j}=\left(\Delta Z_{i, k}^{o b s}\right)^{j}+v_{\Delta Z}^{j}
\end{aligned}
$$

where $j=0,1,2,3 \ldots$ are measuring epochs, and $i \neq k$.

Denoting the vector of adjusted observations $\Delta \hat{\mathbf{X}}=\left[\Delta \hat{X}_{i, k}, \Delta \hat{Y}_{i, k}, \Delta \hat{Z}_{i, k}\right]^{\mathrm{T}}$, the vector of observations $\mathbf{I}=\left[\Delta X_{i, k}^{o b s}, \Delta Y_{i, k}^{o b s}, \Delta Z_{i, k}^{o b s}\right]^{\mathrm{T}}$, and the vector of residuals $\mathbf{v}=\left[v_{\Delta X}, v_{\Delta Y}, v_{\Delta Z}\right]^{\mathrm{T}}$, relation (1) takes the form

$$
\Delta \hat{\mathbf{X}}^{j}=\mathbf{l}^{j}+\mathbf{v}^{j}
$$

The system observation equations for GPS measurements obtained in unstable reference system has the following form (Kamiński, 2008a, 2009)

$$
\begin{aligned}
v_{\Delta X}^{j} & =s_{X_{k}}^{j}-s_{X_{i}}^{j}+\left(Y_{k}^{j=0}-Y_{i}^{j=0}\right) \varepsilon_{Z}^{j}-\left(Z_{k}^{j=0}-Z_{i}^{j=0}\right) \varepsilon_{Y}^{j}-\left(\Delta X_{i, k}^{o b s}\right)^{j} \\
v_{\Delta Y}^{j} & =s_{Y_{k}}^{j}-s_{Y_{i}}^{j}-\left(X_{k}^{j=0}-X_{i}^{j=0}\right) \varepsilon_{Z}^{j}+\left(Z_{k}^{j=0}-Z_{i}^{j=0}\right) \varepsilon_{X}^{j}-\left(\Delta Y_{i, k}^{b s}\right)^{j} \\
v_{\Delta Z}^{j} & =s_{Z_{k}}^{j}-s_{Z_{i}}^{j}+\left(X_{k}^{j=0}-X_{i}^{j=0}\right) \varepsilon_{Y}^{j}-\left(Y_{k}^{j=0}-Y_{i}^{j=0}\right) \varepsilon_{X}^{j}-\left(\Delta Z_{i, k}^{o b s}\right)^{j}
\end{aligned}
$$

Let us assume further a stochastic model $\mathbf{C}_{\mathbf{l}}=m_{0}^{2} \mathbf{Q}=m_{0}^{2} \mathbf{P}^{-1}$, where $\mathbf{C}_{\mathbf{l}}$ is a quasidiagonal covariance matrix of observations, $\mathbf{Q}=\mathbf{P}^{-1}$ is a cofactor matrix (variance approximation) and $m_{0}^{2}$ is an unknown covariance factor.

The DiSTFA method corresponds to the following adjustment problem (Kamiński, 2008a, 2009)

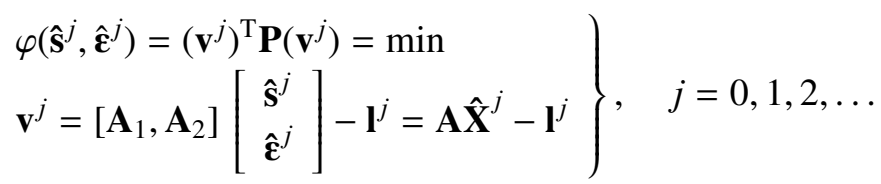

where $\varphi(\bullet)$ is the objective function of the adjustment problem, $\mathbf{A}=\left[\mathbf{A}_{1}, \mathbf{A}_{2}\right]^{\mathrm{T}}$ are known design matrices, $\hat{\mathbf{X}}=\left[\hat{\mathbf{s}}^{j}, \hat{\boldsymbol{\varepsilon}}^{j}\right]^{\mathrm{T}}$ is a vector of estimated parameters.

Due to lack of points of reference the calculations should be performed using the free network adjustment approach.

The problem (4) can be solved by the estimator $\hat{\mathbf{X}}$ of the following form

$$
\hat{\mathbf{X}}^{j}=\left[\begin{array}{c}
\hat{\mathbf{s}}^{j} \\
\hat{\varepsilon}^{j}
\end{array}\right]=\left[\begin{array}{cc}
\mathbf{A}_{1}^{\mathrm{T}} \mathbf{P} \mathbf{A}_{1} & \mathbf{A}_{1}^{\mathrm{T}} \mathbf{P} \mathbf{A}_{2} \\
\mathbf{A}_{2}^{\mathrm{T}} \mathbf{P} \mathbf{A}_{1} & \mathbf{A}_{2}^{\mathrm{T}} \mathbf{P} \mathbf{A}_{2}
\end{array}\right]^{-}\left[\begin{array}{c}
\mathbf{A}_{1}^{\mathrm{T}} \mathbf{P} \mathbf{I} \\
\mathbf{A}_{2}^{\mathrm{T}} \mathbf{P I}
\end{array}\right]
$$

where $[\bullet]^{-}$means $g$-inverse of a matrix, with the covariance matrix

$$
\mathbf{C}_{\hat{\mathbf{X}}}=m_{0}^{2} \mathbf{Q}_{\hat{\mathbf{X}}}
$$


where

$$
\mathbf{Q}_{\hat{\mathbf{X}}}=\left[\begin{array}{cc}
\mathbf{A}_{1}^{\mathrm{T}} \mathbf{P} \mathbf{A}_{1} & \mathbf{A}_{1}^{\mathrm{T}} \mathbf{P} \mathbf{A}_{2} \\
\mathbf{A}_{2}^{\mathrm{T}} \mathbf{P} \mathbf{A}_{1} & \mathbf{A}_{2}^{\mathrm{T}} \mathbf{P} \mathbf{A}_{2}
\end{array}\right]^{-}
$$

and $m_{0}^{2}=\left(\mathbf{v}^{j}\right)^{\mathrm{T}} \mathbf{P}\left(\mathbf{v}^{j}\right) / f ; f=n-r+d-$ number of degrees of freedom; $n$ - number of observations; $r$ - number of unknowns; $d$ - network defect.

In order to apply the DiSTFA method in analyses allowing the detection of observations suspected of gross errors, a covariance matrix of residuals $\mathbf{C}_{\mathbf{v}}$ should be established. The matrix $\mathbf{C}_{\mathbf{v}}$ will take the following form (Kamiński, 2009)

$$
\mathbf{C}_{\mathbf{v}}=m_{0}^{2} \mathbf{Q}_{\mathbf{v}}
$$

with the cofactor matrix $\mathbf{Q}_{\mathbf{v}}$

$$
\mathbf{Q}_{\mathbf{v}}=\left(\mathbf{P}^{-1}-\mathbf{A} \mathbf{Q}_{\hat{\mathbf{X}}} \mathbf{A}^{\mathrm{T}}\right)
$$

Estimated parameters $\hat{\mathbf{X}}=\left[\hat{\mathbf{s}}^{j}, \hat{\boldsymbol{\varepsilon}}^{j}\right]^{\mathrm{T}}$ are later used to calculate displacements and strains (Kamiński, 2009). A broad description of the issue concerning the determination of displacements and strains, as well as parameters describing them is widely described in literature (e.g. Lazzarini et al., 1977; Brunner, 1979; Czaja, 1992; Wu and Chen, 2002; Szostak-Chrzanowski et al., 2006; Chrzanowski and Wilkins, 2006; Prószyński and Kwaśniak, 2006).

\section{The DiSTFAG method robust to gross errors}

In the adjustment of networks surveyed using GPS technology, the cofactor matrix $\mathbf{Q}$, $\left(\mathbf{Q}=\mathbf{P}^{-1}\right)$ has a quasi-diagonal form

$$
\mathbf{Q}=\operatorname{diag}\left(\mathbf{Q}_{1}, \mathbf{Q}_{2}, \mathbf{Q}_{i}, \ldots, \mathbf{Q}_{t}\right)=\left[\begin{array}{ccccc}
\mathbf{Q}_{1} & 0 & 0 & 0 & 0 \\
0 & \mathbf{Q}_{2} & 0 & 0 & 0 \\
0 & 0 & \mathbf{Q}_{i} & 0 & 0 \\
0 & 0 & 0 & n & 0 \\
0 & 0 & 0 & 0 & \mathbf{Q}_{t}
\end{array}\right]
$$

where

$$
\mathbf{Q}_{i}=\left[\begin{array}{ccc}
m_{\Delta X}^{2} & \operatorname{cov}(\Delta X, \Delta Y) & \operatorname{cov}(\Delta X, \Delta Z) \\
\operatorname{cov}(\Delta Y, \Delta X) & m_{\Delta Y}^{2} & \operatorname{cov}(\Delta Y, \Delta Z) \\
\operatorname{cov}(\Delta Z, \Delta X) & \operatorname{cov}(\Delta Z, \Delta Y) & m_{\Delta Z}^{2}
\end{array}\right]
$$

is a block matrix of correlated observations, and $i=1,2, \ldots, t ;(n=3 t)$.

Consequently, robust methods, proposed for correlated observations, should be used to detect gross errors. A number of such robust methods have been presented in literature (e.g. Xu, 1989; Yang, 1994; Yang et al., 2002). 
While estimating with the use of robust methods, it is generally necessary to determine the acceptable range for random measurement errors $\langle-a, a\rangle$, e.g. applying the relation (Hampel et al., 1986)

$$
2 \Phi^{R N}(a)-1+2 f_{l}^{R N}(a) / a=1 /\left(1-\alpha_{v}\right) \cong n /(n-\kappa)
$$

where $\Phi^{R N}(\bullet)$ is a normal distribution function, $f_{l}^{R N}(\bullet)$ is a density function of standardized normal distribution, $n$ is a number of observations, $\kappa$ is a number of observations suspected of gross errors, $\alpha_{v} \cong \kappa / n$ is a coefficient determining gross errors (Tukey, 1960).

When determining the acceptable range for random measurement errors, one can also use the probability $\gamma$ with which random variable $\bar{v}\left(\bar{v}_{i}=\left|v_{i}\right| / m_{v_{i}} ; m_{v_{i}}=\sqrt{\left.\left[\mathbf{Q}_{\mathbf{v}}\right)\right]_{i, i}}\right)$, fits within the acceptable range

$$
P(-a \leq \bar{v} \leq a)=\gamma
$$

For example, if $a=1.5$ then $\gamma=0.866$, if $a=2.0$ then $\gamma=0.954$, if $a=3$ then $\gamma=0.996$.

Due to applying the acceptable range $\langle-a, a\rangle$ observation weights (for which standardised corrections $\bar{v}$ fit into the acceptable range) remain unchanged. They are, however, modified by weight functions $w\left(v_{i, j}\right)=\psi_{i}\left(v_{i}, v_{j}\right) / v_{i}$, where $\psi_{i}\left(v_{i}, v_{j}\right)=\partial \rho\left(v_{i}, v_{j}\right) / \partial v_{i}$, $(i, j=1,2, \ldots, n)$ established for various methods (Xu, 1989; Yang, 1994). Various forms of such weight functions are specified for correlated observations (e.g. Xu, 1989; Yang, 1994).

In the present study, a weight function of the following form is applied (Xu, 1989)

$$
w\left(\bar{v}_{i, j}\right)= \begin{cases}1 & \bar{v}_{i} \leq a \text { and } \bar{v}_{j} \leq a \\ {\left[\exp \left(d\left|\bar{v}_{i, i}\right|\right)\right]^{-1}} & \bar{v}_{i}>a \text { or } \bar{v}_{j}>a\end{cases}
$$

where $a, d$ are positive coefficients.

Since the aim of the present study is only to prove the resistance of the DiSTFA method to gross errors, any other forms of weight functions will not be discussed in detail. The issue of the most advisable choice of functions for weight coefficients will be analysed in subsequent studies by the author.

With weight functions $w\left(\bar{v}_{i, j}\right)$, weight modification can be carried out in the following way

$$
\begin{aligned}
& \bar{p}_{i, i}=p_{i, i} w\left(\bar{v}_{i, i}\right) \\
& \bar{p}_{i, j}=p_{i, j} w\left(\bar{v}_{i, j}\right)
\end{aligned}
$$

The adjustment problem (4) will thus take the following form

$$
\left.\begin{array}{l}
\varphi\left(\hat{\mathbf{s}}^{j}, \hat{\boldsymbol{\varepsilon}}^{j}\right)=\left(\mathbf{v}^{j}\right)^{\mathrm{T}} \overline{\mathbf{P}}\left(\mathbf{v}^{j}\right)=\min \\
\mathbf{v}^{j}=\left[\mathbf{A}_{1}, \mathbf{A}_{2}\right]\left[\begin{array}{c}
\hat{\mathbf{s}}^{j} \\
\hat{\boldsymbol{\varepsilon}}^{j}
\end{array}\right]-\mathbf{l}^{j}=\mathbf{A} \hat{\mathbf{X}}^{j}-\mathbf{l}^{j}
\end{array}\right\}
$$


where $\overline{\mathbf{P}}$ is an equivalent weight matrix the elements of which (equivalent weights) are determined from (15). The search for a solution with the application of the DiSTFAG method resistant to gross errors is conducted in two main stages.

The first stage

Preliminary adjustment (for each measuring epoch $j=0,1,2, \ldots$ )

$$
\left.\begin{array}{l}
\hat{\mathbf{X}}^{(k)}=\mathbf{Q}_{\hat{\mathbf{X}}} \mathbf{A}^{\mathrm{T}} \overline{\mathbf{P}}^{(k)} \mathbf{l}^{(k)} \\
\mathbf{v}^{(k)}=\mathbf{A} \hat{\mathbf{X}}^{(k)}-\mathbf{l}^{(k)} \\
\mathbf{Q}_{\mathbf{v}}^{(k)}=-\mathbf{A} \mathbf{Q}_{\hat{\mathbf{X}}} \mathbf{A}^{\mathrm{T}} \\
m_{0}^{2}=\left(\mathbf{v}^{\mathrm{T}} \overline{\mathbf{P}}^{(k)} \mathbf{v}\right) / f \\
\mathbf{C}_{\mathbf{v}}^{(k)}=m_{0}^{2} \mathbf{Q}_{\mathbf{v}}^{(k)} \\
m_{i, i}^{(k)}=\sqrt{\left[\mathbf{Q}_{\mathbf{v}}^{(k)}\right]_{i, i},} \quad \bar{v}_{i}^{(k)}=v_{i}^{(k)} / m_{v_{i, i}}^{(k)}
\end{array}\right\}
$$

with $k=0,1,2,3 \ldots$ ( $k$ - number of iterations $)$.

Starting the iteration process $(k=0), \overline{\mathbf{P}}^{(k=0)}=\mathbf{P}$ is assumed. The iteration procedure ends when standardised corrections fit into the acceptable range $\left(\left|\bar{v}_{i}\right| \leq a\right)$ for each observation. The corrections for observations suspected of gross errors obtained from the final iteration are then added to the observed values, making corrected (by gross errors) observations.

The second stage

Observations corrected for gross errors are adjusted with the use of the DiSTFA method. Due to the limits of the present study, this issue will not be discussed further. More information on this process can be found in (Kamiński, 2009).

\section{Example of practical application}

Theoretical considerations were verified on a 3D test network with simulated GPS measurements (Fig. 1).

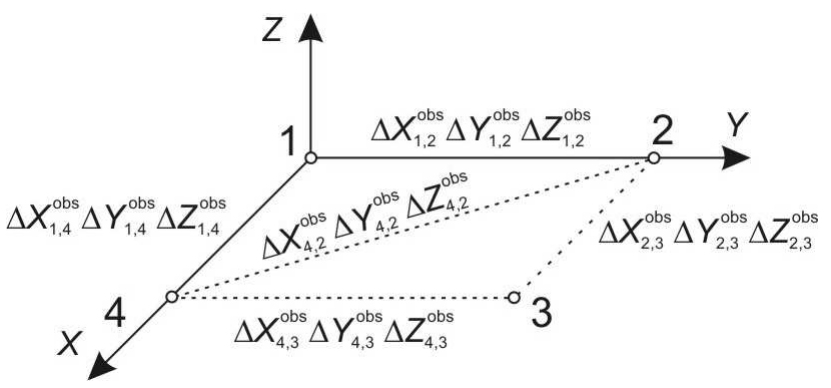

Fig. 1. Test network 
It has been assumed that

$$
\mathbf{A}_{1}=\left[\begin{array}{rrrrrrrrrrrr}
-1 & 0 & 0 & 1 & 0 & 0 & 0 & 0 & 0 & 0 & 0 & 0 \\
0 & -1 & 0 & 0 & 1 & 0 & 0 & 0 & 0 & 0 & 0 & 0 \\
0 & 0 & -1 & 0 & 0 & 1 & 0 & 0 & 0 & 0 & 0 & 0 \\
0 & 0 & 0 & -1 & 0 & 0 & 1 & 0 & 0 & 0 & 0 & 0 \\
0 & 0 & 0 & 0 & -1 & 0 & 0 & 1 & 0 & 0 & 0 & 0 \\
0 & 0 & 0 & 0 & 0 & -1 & 0 & 0 & 1 & 0 & 0 & 0 \\
0 & 0 & 0 & 0 & 0 & 0 & 1 & 0 & 0 & -1 & 0 & 0 \\
0 & 0 & 0 & 0 & 0 & 0 & 0 & 1 & 0 & 0 & -1 & 0 \\
0 & 0 & 0 & 0 & 0 & 0 & 0 & 0 & 1 & 0 & 0 & -1 \\
-1 & 0 & 0 & 0 & 0 & 0 & 0 & 0 & 0 & 1 & 0 & 0 \\
0 & -1 & 0 & 0 & 0 & 0 & 0 & 0 & 0 & 0 & 1 & 0 \\
0 & 0 & -1 & 0 & 0 & 0 & 0 & 0 & 0 & 0 & 0 & 1 \\
0 & 0 & 0 & 1 & 0 & 0 & 0 & 0 & 0 & -1 & 0 & 0 \\
0 & 0 & 0 & 0 & 1 & 0 & 0 & 0 & 0 & 0 & -1 & 0 \\
0 & 0 & 0 & 0 & 0 & 1 & 0 & 0 & 0 & 0 & 0 & -1
\end{array}\right]
$$

and the weight matrix $\mathbf{P}$

$$
\mathbf{P}=\operatorname{diag}\left(\mathbf{P}_{1}, \mathbf{P}_{2}, \mathbf{P}_{3}, \mathbf{P}_{4}, \mathbf{P}_{5}\right), \text { where } \mathbf{P}_{i}=\left[\begin{array}{rrr}
1.0 & 0.5 & 0.5 \\
0.5 & 1.0 & 0.5 \\
0.5 & 0.5 & 1.0
\end{array}\right], i=1,2,3,4,5
$$

was applied. 
The parameters to be estimated are the components of vectors

$\mathbf{s}=\left[s_{X_{1}}, s_{Y_{1}}, s_{Z_{1}}, s_{X_{2}}, s_{Y_{2}}, s_{Z_{2}}, s_{X_{3}}, s_{Y_{3}}, s_{Z_{3}}, s_{X_{4}}, s_{Y_{4}}, s_{Z_{4}}\right]^{\mathrm{T}}$, and $\boldsymbol{\varepsilon}=\left[\varepsilon_{X}, \varepsilon_{Y}, \varepsilon_{Z}\right]^{\mathrm{T}}$

Calculations were carried out in the following variants:

- initial measurement $(j=0)$,

- variant I - actual measurement ,,$j$ " without a gross error,

- variant II - actual measurement , $j "$ with a gross error.

Simulating the results of an actual measurement taking into consideration the instability of the reference system (variant I), a 6-parameter transformation of the following form was applied

$$
\begin{aligned}
X_{i}^{j} & =T_{X}+X_{i}+\varepsilon_{Z}^{j} Y_{i}-\varepsilon_{Y}^{j} Z_{i} \\
Y_{i}^{j} & =T_{Y}-\varepsilon_{Z}^{j} X_{i}+Y_{i}+\varepsilon_{X}^{j} Z_{i} \\
Z_{i}^{j} & =T_{Z}+\varepsilon_{Y}^{j} X_{i}-\varepsilon_{X}^{j} Y_{i}+Z_{i}
\end{aligned}
$$

It has been assumed that the reference system subsided by $1 \mathrm{~cm}$ along each coordinate axis, therefore the translation parameters $T_{X}=T_{Y}=T_{Z}=-0.01 \mathrm{~m}$. It was also subject to rotation and the values of rotation angles assumed for transformations were $\varepsilon_{X}=\varepsilon_{Y}=\varepsilon_{Z}=0.0004^{c c}$.

Simulations of variant II measurements used data from variant I, and it was assumed that the following observations were contaminated by gross errors: $\Delta X_{4,2}^{o b s}=-700.042 \mathrm{~m}$ (gross error $-0.04 \mathrm{~m}$ ) instead of $\Delta X_{4,2}^{\text {obs }}=-700.002 \mathrm{~m}$ and $\Delta Z_{4,2}^{\text {obs }}=0.021 \mathrm{~m}$ instead of $\Delta Z_{4,2}^{\text {obs }}=-0.021 \mathrm{~m}$ (gross error of $0.042 \mathrm{~m}$ ). Table 1 presents simulated results of observations used for further analyses.

Table 1. Simulated results of measurements

\begin{tabular}{|c|r|r|r|}
\hline Vector components & $\begin{array}{c}\text { Primary measurement } \\
{[\mathrm{m}]}\end{array}$ & $\begin{array}{c}\text { Variant I } \\
{[\mathrm{m}]}\end{array}$ & $\begin{array}{c}\text { Variant II } \\
{[\mathrm{m}]}\end{array}$ \\
\hline$\Delta X_{1,2}^{\text {obs }}$ & 0.002 & -0.003 & 0.003 \\
\hline$\Delta Y_{1,2}^{\text {bs }}$ & 799.997 & 799.987 & 799.987 \\
\hline$\Delta Z_{1,2}^{\text {obs }}$ & 0.001 & -0.014 & -0.014 \\
\hline$\Delta X_{2,3}^{\text {obs }}$ & 699.999 & 699.989 & 699.989 \\
\hline$\Delta Y_{2,3}^{\text {obs }}$ & 0.002 & -0.012 & -0.012 \\
\hline$\Delta Z_{2,3}^{\text {obs }}$ & -0.003 & -0.009 & -0.009 \\
\hline$\Delta X_{4,3}^{\text {obs }}$ & 0.003 & -0.002 & -0.002 \\
\hline$\Delta Y_{4,3}^{\text {obs }}$ & 799.998 & 799.988 & 799.988 \\
\hline$\Delta Z_{4,3}^{\text {os }}$ & 0.001 & -0.014 & -0.014 \\
\hline$\Delta X_{1,4}^{\text {bs }}$ & 700.002 & 699.992 & 699.992 \\
\hline$\Delta Y_{1,4}^{\text {obs }}$ & -0.002 & -0.016 & -0.016 \\
\hline$\Delta Z_{1,4}^{\text {obs }}$ & 0.003 & -0.003 & -0.003 \\
\hline$\Delta X_{4,2}^{\text {bs }}$ & -699.997 & -700.002 & $-\mathbf{7 0 0 . 0 4 2}$ \\
\hline$\Delta Y_{4,2}^{\text {obs }}$ & 800.003 & 799.997 & 799.997 \\
\hline$\Delta Z_{4,2}^{\text {obs }}$ & -0.002 & -0.021 & $\mathbf{0 . 0 2 1}$ \\
\hline
\end{tabular}


While carrying out calculations using the DiSTFAG method, the weight function (14) (Xu, 1989) was used with $d=3.5$. Calculated corrections, their mean errors and the process of standardization are presented in Table 2.

Table 2. Standardization process

\begin{tabular}{|c|c|c|c|c|c|}
\hline Correction & $\begin{array}{c}\text { Starting } \\
\text { measurement }\end{array}$ & I & II & IIa & $\mathrm{II}^{G}$ \\
\hline$\left|v_{1}\right| / m_{v_{1}}$ & $1.2 / 2.2=0.54$ & $1.2 / 6.9=0.17$ & $11.2 / 13.6=0.82$ & $2.7 / 7.1=0.38$ & $1.3 / 2.2=0.59$ \\
\hline$\left|v_{2}\right| / m_{v_{2}}$ & $0.6 / 2.2=0.27$ & $1.9 / 6.9=0.28$ & $1.9 / 13.6=0.13$ & $1.3 / 8.1=0.16$ & $2.1 / 2.6=0.81$ \\
\hline$\left|v_{3}\right| / m_{v_{3}}$ & $0.7 / 2.2=0.32$ & $1.8 / 6.9=0.26$ & $8.8 / 13.6=0.64$ & $9.4 / 8.1=1.16$ & $2.1 / 2.2=0.95$ \\
\hline$\left|v_{4}\right| / m_{v_{4}}$ & $0.8 / 2.2=0.36$ & $3.2 / 6.9=0.46$ & $13.2 / 13.6=0.97$ & $4.8 / 7.1=0.68$ & $0.7 / 2.2=0.32$ \\
\hline$\left|v_{5}\right| / m_{v_{5}}$ & $2.1 / 2.2=0.95$ & $0.4 / 6.9=0.06$ & $0.4 / 13.6=0.02$ & $0.2 / 8.1=0.02$ & $0.6 / 2.6=0.23$ \\
\hline$\left|v_{6}\right| / m_{v_{6}}$ & $2.2 / 2 / 2=1.00$ & $4.8 / 6.9=0.70$ & $5.8 / 13.6=0.42$ & $6.4 / 8.1=0.79$ & $0.9 / 2.2=0.41$ \\
\hline$\left|v_{7}\right| / m_{v_{7}}$ & $0.8 / 2.2=0.36$ & $3.2 / 6.9=0.46$ & $13.2 / 13.6=0.97$ & $4.8 / 7.1=0.68$ & $0.7 / 2.2=0.32$ \\
\hline$\left|v_{8}\right| / m_{v_{8}}$ & $2.1 / 2 / 2=0.95$ & $0.4 / 6.9=0.06$ & $0.4 / 13.6=0.03$ & $0.2 / 8.1=0.02$ & $0.6 / 2.6=0.23$ \\
\hline$\left|v_{9}\right| / m_{v_{9}}$ & $2.3 / 2.2=1.04$ & $4.8 / 6.9=0.70$ & $5.7 / 13.6=0.42$ & $6.4 / 8.1=0.79$ & $0.9 / 2.2=0.41$ \\
\hline$\left|v_{10}\right| / m_{v_{10}}$ & $1.2 / 2.2=0.54$ & $1.2 / 6.9=0.17$ & $11.2 / 13.6=0.82$ & $2.8 / 7.1=0.39$ & $1.3 / 2.2=0.59$ \\
\hline$\left|v_{11}\right| / m_{v_{11}}$ & $0.6 / 2.2=0.27$ & $1.9 / 6.9=0.28$ & $1.9 / 13.6=0.14$ & $1.3 / 8.1=0.16$ & $2.1 / 2.6=0.80$ \\
\hline$\left|v_{12}\right| / m_{v_{12}}$ & $0.8 / 2.2=0.36$ & $1.8 / 6.9=0.26$ & $8.8 / 13.6=0.64$ & $9.4 / 8.1=1.16$ & $2.1 / 2.2=0.95$ \\
\hline$\left|v_{13}\right| / m_{v_{13}}$ & $0.5 / 2.6=0.19$ & $4.5 / 8.0=0.56$ & $24.5 / 15.6=1.57$ & $41.5 / 167.9=0.25$ & $49.6 / 53.9=0.92$ \\
\hline$\left|v_{14}\right| / m_{v_{14}}$ & $2.8 / 2.6=1.08$ & $2.2 / 8.0=0.28$ & $2.2 / 15.6=0.14$ & $3.5 / 8.5=0.41$ & $1.8 / 2.2=0.82$ \\
\hline$\left|v_{15}\right| / m_{v_{15}}$ & $1.5 / 2.6=0.58$ & $6.5 / 8.0=0.81$ & $14.5 / 15.6=0.92$ & $13.3 / 8.5=1.56$ & $27.8 / 53.9=0.52$ \\
\hline
\end{tabular}

Variant IIa (Table 2) illustrates the results of adjustment obtained after the first iteration, while variant $\mathrm{II}^{G}$ - results of estimation obtained after iteration ending the first stage of calculations. In the iterations $a=1.5$ was used

Results presented in Table 2 show that in variant II (with a gross error) the correction $\left|v_{13}\right| / m_{v_{13}}=1.57$ exceeds the acceptable range specified for random measurement errors. The process of weight modification should thus be carried out with the use of (14).

The corrections for observations suspected of gross errors obtained from the final $\left(\mathrm{II}^{G}\right)$ iteration should then be added to the direct results of observations. The corrected results of the primary measurement amount to

$$
\begin{aligned}
\Delta X_{4,2}^{o b s} & =-700.0420 \mathrm{~m}+0.0496 \mathrm{~m}=-699.9924 \mathrm{~m}, \quad \text { and } \\
\Delta Z_{4,2}^{o b s} & =0.0210 \mathrm{~m}-0.0278 \mathrm{~m}=-0.0068 \mathrm{~m} .
\end{aligned}
$$

In the second stage of estimation corrected measurements are adjusted with the starting weights (before modification by the weight function) (Table 3). Variant $\mathrm{II}^{M}$ indicates results obtained from the observed values adjusted for gross errors in stage one.

Differences between the values of vector components in variants II - I and $\mathrm{II}^{M}-\mathrm{I}$ are shown in Table 4. 
Table 3. Adjusted measurement results

\begin{tabular}{|c|r|r|r|r|}
\hline $\begin{array}{c}\text { Vector } \\
\text { component }\end{array}$ & $\begin{array}{c}\text { Starting measurement } \\
{[\mathrm{m}]}\end{array}$ & \multicolumn{1}{c|}{$\begin{array}{c}\text { I } \\
{[\mathrm{m}]}\end{array}$} & \multicolumn{1}{c|}{$\begin{array}{c}\text { II } \\
{[\mathrm{m}]}\end{array}$} & \multicolumn{1}{c|}{$\begin{array}{c}\text { II } \\
{[\mathrm{m}]}\end{array}$} \\
\hline$\Delta \hat{X}_{1,2}$ & 0.003 & 0.001 & -0.009 & 0.003 \\
\hline$\Delta \hat{Y}_{1,2}$ & 799.998 & 799.995 & 799.995 & 799.995 \\
\hline$\Delta \hat{Z}_{1,2}$ & 0.002 & -0.001 & 0.010 & 0.003 \\
\hline$\Delta \hat{X}_{2,3}$ & 700.000 & 700.002 & 700.012 & 700.000 \\
\hline$\Delta \hat{Y}_{2,3}$ & 0.000 & 0.002 & 0.002 & 0.002 \\
\hline$\Delta \hat{Z}_{2,3}$ & 0.001 & 0.002 & -0.009 & -0.002 \\
\hline$\Delta \hat{X}_{4,3}$ & 0.002 & 0.000 & -0.010 & 0.002 \\
\hline$\Delta \hat{Y}_{4,3}$ & 800.000 & 799.998 & 799.998 & 799.998 \\
\hline$\Delta \hat{Z}_{4,3}$ & -0.001 & -0.004 & 0.007 & 0.000 \\
\hline$\Delta \hat{X}_{1,4}$ & 700.001 & 700.003 & 700.013 & 700.001 \\
\hline$\Delta \hat{Y}_{1,4}$ & -0.003 & 0.000 & 0.000 & 0.000 \\
\hline$\Delta \hat{Z}_{1,4}$ & 0.002 & 0.005 & -0.006 & 0.001 \\
\hline$\Delta \hat{X}_{4,2}$ & -699.998 & -699.992 & $-\mathbf{6 9 9 . 9 7 2}$ & $-\mathbf{6 9 9 . 9 9 7}$ \\
\hline$\Delta \hat{Y}_{4,2}$ & 800.000 & 800.005 & 800.005 & 800.005 \\
\hline$\Delta \hat{Z}_{4,2}$ & 0.000 & 0.004 & $\mathbf{- 0 . 0 1 6}$ & $-\mathbf{0 . 0 0 3}$ \\
\hline
\end{tabular}

Table 4. Differences between adjusted vector components

\begin{tabular}{|c|c|c|}
\hline $\begin{array}{c}\text { Vector } \\
\text { component }\end{array}$ & $\begin{array}{c}\text { II }- \text { I } \\
{[\mathrm{mm}]}\end{array}$ & $\begin{array}{c}\mathrm{II}^{M}-\mathrm{I} \\
{[\mathrm{mm}]}\end{array}$ \\
\hline$\Delta \hat{X}_{1,2}$ & -10 & 2 \\
\hline$\Delta \hat{Y}_{1,2}$ & 0 & 0 \\
\hline$\Delta \hat{Z}_{1,2}$ & 11 & 4 \\
\hline$\Delta \hat{X}_{2,3}$ & 10 & 2 \\
\hline$\Delta \hat{Y}_{2,3}$ & 0 & 0 \\
\hline$\Delta \hat{Z}_{2,3}$ & 11 & 4 \\
\hline$\Delta \hat{X}_{4,3}$ & -10 & 2 \\
\hline$\Delta \hat{Y}_{4,3}$ & 0 & 0 \\
\hline$\Delta \hat{Z}_{4,3}$ & 11 & 4 \\
\hline$\Delta \hat{X}_{1,4}$ & 10 & -2 \\
\hline$\Delta \hat{Y}_{1,4}$ & 0 & 0 \\
\hline$\Delta \hat{Z}_{1,4}$ & 11 & -4 \\
\hline$\Delta \hat{X}_{4,2}$ & $\mathbf{2 0}$ & $\mathbf{5}$ \\
\hline$\Delta \hat{Y}_{4,2}$ & 0 & 0 \\
\hline$\Delta \hat{Z}_{4,2}$ & $\mathbf{2 0}$ & $-\mathbf{7}$ \\
\hline & & \\
\hline
\end{tabular}


Results presented in Table 4 show that by applying the algorithm proposed in this paper, better results were obtained in variant $\mathrm{II}^{M}$.

Further calculations concerning displacements can be carried out in the way presented e.g. in (Kamiński, 2009).

\section{Conclusions}

The present paper puts forward a proposal for making the DiSTFA method robust to observations contaminated by gross errors. The method proposed has been named DiSTFAG. The DiSTFAG method makes it possible to carry out specialised analyses in cases when measurements are taken in unstable reference systems and there is a suspicion that the observations could be contaminated by gross errors.

The following general conclusions can be drawn from the analyses performed on the simulated surveying network:

1. The DiSTFAG method can be used for detection of the observations suspected of the gross errors.

2. In case the gross errors occurs in the network the calculation algorithm consists of 2 stages:

- stage 1 is the initial adjustment, in which the observations suspected of gross errors are pointed out and the measurement results are corrected;

- stage 2 is the use of the DiSTFA method and pointing out the displacement and strains.

3. From the data presented in Table 4, it can be deduced that after using the two-stage and robust to gross errors DiSTFAG method the results (vectors' components) obtained are better and are within the range of $<-7 \mathrm{~mm} ; 5 \mathrm{~mm}>$, while the results obtained from a non-robust method are within the range of $<-20 \mathrm{~mm} ; 20 \mathrm{~mm}>$.

4. The possibility of the gross errors detection (while detecting the displacements and strains) that is done on the basis of the surveying observations made using only one measurement technology is one of the important advantages of the DiSTFAG method. There could be situations in which there will be impossible to repeat the measurements contaminated by gross errors (including the measurements necessary for the proper interpretation of results).

The presented example of practical application signals only the need for more detailed theoretical and empirical analyses. The main problem concerns the choice of the most favourable form of the weight function determined for correlated observations so that the observations suspected of gross errors could be identified. Additionally, a series of analyses should be carried out on actual surveying networks. These issues will be the subject of more detailed further research conducted by the author. 


\section{Acknowledgments}

The present study has been carried out as part of the statutory research No. 528-0302-0806 conducted at the Institute of Geodesy of the University of Warmia and Mazury in Olsztyn. The author would like to thank Prof. Jan Kryński, for his comments, indispensable for preparing the final version of the study, as well as two anonymous reviewers for valuable remarks.

\section{References}

Brunner F.K., (1979): On the analysis of geodetic networks for the determination of the incremental strain tensor, Survey Review, Vol. XXV, No 192, pp. 56-67.

Chen Y.Q., Chrzanowski A., Secrod J.M., (1990): A strategy for the analysis of the stability of reference points in deformation surveys, CISM Journal, Vol. 44, No 2, Summer, pp. 39-46.

Czaja J., (1992): Engineering and industrial geodesy. Collection of examples and problems. Part II. $4^{\text {th }}$ edition - supplemented (in Polish), Wydawnictwa AGH, Krakow.

Chrzanowski A., Wilkins R., (2006): Accuracy evaluation of geodetic monitoring of deformations in large open pit mines, $3^{\text {th }}$ IGS Symposium on Geodesy for Geotechnical and Structural Engineering and $12^{\text {th }}$ FIG Symposium on Deformation Measurements, Baden, Austria, 22 - 24 May.

Gökalp E., Tasci L., (2009): Deformation monitoring by GPS at embankment dams and deformation analysis, Survey Review, Vol. 41, No 311, pp. 86-102.

Hampel F.R., Ronchetti E.M., Rousseeuw P.J., Stahel W.A., (1986): Robust statistics. An approach based on influence functions, John Wiley and Sons, New York.

Kamiński W., (2008a): The Idea of Monitoring Surface Deformations on Unstable Ground with the Use of GPS Technology, Bolletino di Geodesia e Scienze Affini, No 1, pp. 33-45.

Kamiński W., (2008b): The Conception of Monitoring the Superficial Deformation Located on the Unstable Foundation with the Usage of GPS Technology, $13^{\text {th }}$ FIG International Symposium on Deformation Measurements and Analysis, $4^{\text {th }}$ Symposium on Geodesy for Geotechnical and Structural Engineering, Lisbon, 12 - 15 May (CD).

Kamiński W., (2009): Properties and analysis of the accuracy of estimation results obtained by the DiSTFA method in monitoring displacements and strains, Geodesy and Cartography, Vol. 58, No 2, pp. 37-50.

Lazzarini T., Laudyn I., Chrzanowski A., Gaździcki J., Janusz W., Wiłun Z., Mayzel B., Mikucki Z., (1977): Geodetic measurements of displacements of structures and their surroundings (in Polish), PPWK, Warsaw.

Prószyński W., Kwaśniak M., (2006): Bases for geodetic determination of displacements. Notions and methodology elements (in Polish), Oficyna Wydawnicza Politechniki Warszawskiej, Warszawa.

Szostak-Chrzanowski A., Prószyński W., Gambin W., (2006): Continuum mechanics as a support for deformation monitoring, analysis, and interpretation, $3^{\text {th }}$ IGS Symposium on Geodesy for Geotechnical and Structural Engineering and $12^{\text {th }}$ FIG Symposium on Deformation Measurements. Baden, Austria, 22 - 24 May.

Tukey J.W., (1960): A survey of sampling from contaminated distribution in: Contributions to Probability and Statistics, I. Olhin, Standford University Press, California.

Vaniček P., Craymer M.R., Krakiwsky J.E., (2001): Robustness analysis of geodetic horizontal networks, Journal of Geodesy, No 75, pp. 199-209.

Wiśniewski Z., (1989): The idea of determination of parameters of location and shape of fundamental plates on the basis of free levelling (in Polish), Proceedings VI Scientific-Technical Session "Current scientific and technical problems of geodetic works", Gdansk -Sobieszewo, 6 - 7 October, pp. 147-173. 
Wu J.C., Chen Y.Q., (2002): Improvement of the separability of a survey scheme for monitoring crustal deformations in the area of an active fault, Journal of Geodesy, Vol. 76, pp. 77-81.

Xu P., (1989): On Robust Estimation with correlated Observations, Bulletin Géodésique, Vol. 63, pp. 237-252.

Yang Y., (1994): Robust Estimation for Dependent Observations, Manuscripta Geodaetica, Vol. 19, pp. 10-17.

Yang Y., Song L.J., Xu T.H., (2002): Robust estimation of correlated observation based on bifactor equivalent weights, Journal of Geodesy, Vol. 76, pp. 353-358.

\title{
Odporna na błędy grube metoda DiSTFAG w monitoringu przemieszczeń i odkształceń w niestabilnych układach odniesienia
}

\section{Waldemar Kamiński}

\author{
Instytut Geodezji \\ Uniwersytet Warmińsko-Mazurski w Olsztynie \\ ul. Oczapowskiego 1, 10-957 Olsztyn \\ e-mail: waldemar.kaminski@uwm.edu.pl
}

\section{Streszczenie}

W niniejszej pracy zaproponowano uodpornienie metody DiSTFA (Displacements and Strains using Transformation and Free Adjustment) na błędy grube. Metodę DiSTFA opracowano do wyznaczania przemieszczeń i odkształceń obiektów inżynierskich w niestabilnych układach odniesienia jak również badania stałości punktów dostosowania. Metoda DiSTFAG jest rozwinięciem metody DiSTFA uwzględniającym w rozwiązaniu obserwacje obarczone błędami grubymi. Teoretyczne rozważania uzupełniono przykładem praktycznego zastosowania na symulowanej, trójwymiarowej osnowie geodezyjnej. 
